\section{RMD Open}

Rheumatic \& Musculoskeletal Diseases

\title{
Association of antiphospholipid antibodies with active digital ulceration in systemic sclerosis
}

Mickaël Martin, ${ }^{\circ}$ Camille Martinez, ${ }^{2}$ Laurent Arnaud, ${ }^{3}$ Jean-Christophe Weber, ${ }^{4}$ Vincent Poindron, ${ }^{5}$ Gilles Blaison, ${ }^{2}$ Pierre Kieffer, ${ }^{6}$ Bernard Bonnotte, ${ }^{7}$ Sabine Berthier, ${ }^{7}$ Denis Wahl, ${ }^{8,9}$ Francois Maurier, ${ }^{10}$ Jean-Loup Pennaforte, ${ }^{11}$ Philip Bielefeld, ${ }^{7}$ Nadine Magy-Bertrand, ${ }^{12}$ Hervé Devilliers, ${ }^{7}$ Thierry Martin ${ }^{5}$

To cite: Martin M, Martinez C, Arnaud L, et al. Association of antiphospholipid antibodies with active digital ulceration in systemic sclerosis. RMD Open 2019;5:e001012. doi:10.1136/ rmdopen-2019-001012

- Additional material is published online only. To view please visit the journal online (http://dx.doi.org/10.1136/ rmdopen-2019-001012).

Received 15 May 2019 Revised 23 August 2019 Accepted 6 September 2019

Check for updates

\section{(c) Author(s) (or their} employer(s)) 2019. Re-use permitted under CC BY-NC. No commercial re-use. See rights and permissions. Published by BMJ.

For numbered affiliations see end of article.

Correspondence to Dr Mickaël Martin; mickael-martin@outlook.com
Raynaud's phenomenon (RP) in systemic sclerosis (SSc) can be severe with active digital ulceration (ADU) and gangrene. RP physiopathology includes early endothelial cell injury, vascular dysfunction and sometimes microvascular thrombosis. ${ }^{1}$ Antiphospholipid antibodies (aPL) activate endothelial cells and platelets by complexes of beta- 2 glycoprotein 1 ( $\beta 2 \mathrm{GP} 1)$ and anti- $\beta 2 \mathrm{GP}^{2}{ }^{2}$ and could therefore contribute to the initiation of and/or aggravate SSc-related RP. aPL prevalence seems increased in patients with SSc compared with controls, ${ }^{3}$ but aPL-associated clinical features are often contradictory. The aims of this study were to assess aPL and antiphospholipid syndrome (APS) prevalence in patients with SSc and their association with ADU.

Consecutive patients aged more than 18 years, fulfilling the American College of Rheumatology/EULAR classification criteria for $\mathrm{SSc}^{4}$ and followed in seven French expert centres for autoimmune diseases labelled by the French national network for autoimmune disease care, were enrolled prospectively during 8 months. Patients with other associated autoimmune disease were excluded. All patients provided written informed consent. SSc subtype was classified based on LeRoy and Medsger's criteria, ${ }^{5}$ and skin involvement was assessed according to the modified Rodnan skin score (mRSS). ${ }^{6}$ Interstitial lung disease (ILD) was defined by subpleural ground-glass opacities and/or interstitial reticular pattern with or without fibrosis on high-resolution CT. Raynaud's activity and the presence of digital ischaemia was determined using a previously published severity score: 0-no Raynaud's; 1-Raynaud's with/without vasodilator required; 2-Digital Pitting Scars; 3-Digital

\section{Key messages}

What is already known about this subject?

- Antiphospholipid antibodies (aPL) prevalence seemed increased in patients with systemic sclerosis (SSc), but their clinical signification is unclear.

What does this study add?

- Description of aPL positivity and antiphospholipid syndrome prevalence in a multicentre cross-sectional SSc cohort (confirmed and high aPL titre level).

- Anti-beta-2 glycoprotein 1 (B2GP1) positivity is an independent factor associated with active digital ulceration.

How might this impact on clinical practice?

- aPL and especially anti- $\beta 2$ GP1 should be screened in SSc to detect patients potentially at higher risk of developing digital ulcers.

Tip Ulcerations and 4-Digital Gangrene. ADU was defined as a score $\geq 3$. ${ }^{8}$ Pulmonary arterial hypertension (PAH) was defined by median pulmonary arterial pressure (mPAP) $\geq 25 \mathrm{~mm} \mathrm{Hg}$ and pulmonary arterial wedge pressure $\leq 15 \mathrm{~mm} \mathrm{Hg}$, not related to lung diseases and/or chronic thromboembolism. Screening for lupus anticoagulant (LA), anticardiolipin (aCL) and anti- $\beta 2$ GP1 antibodies was systematically carried out in each centre and confirmed at least 12 weeks apart. Only persistent aPL were considered. ${ }^{9}$ LA was detected according to the international recommendations. ${ }^{10}$ Positivity for immunoglobulin (Ig) $\mathrm{G} / \mathrm{IgM}$ aCL and anti- $\beta 2 \mathrm{GP} 1$ in immunosorbent assay was defined as 'overall' (titres more than $15-20 \mathrm{U} / \mathrm{mL}$, according to each manufacturer's guidelines) and 'high' (titres $>40 \mathrm{U} / \mathrm{mL}^{9}$ ). APS was diagnosed according to international definition. ${ }^{9}$ Statistical analysis was performed using SAS V.9.4. 
Comparison for scaled variables were performed using Student's t-test. Association between qualitative variables was determined with Pearson's $\chi^{2}$ or Fisher's exact tests. Factors independently associated with ADU were studied by logistic regression model. Dependent variables were selected using a manual backward procedure with $\mathrm{p}=0.05$ as threshold for exit. The procedure initially included all factors associated with severe RP with a p-value below 0.1 in bivariate analysis. Subanalyses were performed considering only 'high' titres of aCL and/or anti- $\beta 2 \mathrm{GP} 1 .^{9}$ The alpha risk was set at $5 \%$ and statistical tests were performed bilaterally with $\mathrm{p}<0.05$ considered as significant. Data are available upon request.

One hundred and sixty-eight patients were included. Their characteristics are summarised in table 1. LA was detected in $17(10 \%)$ patients. Overall, aCL and/or anti$32 \mathrm{GP} 1$ were present in $14(8 \%)$ and $14(8 \%)$ patients, respectively. Positivity for $\geq 1$ aPL was found in $31(18 \%)$ patients and triple positivity in three $(2 \%)$. Seven (4\%) patients had definite APS, without obstetric APS. Anti-Scl70 positivity was more frequent in the APS group ( $71 \%$ vs $34 \%, \mathrm{p}=0.046)$. No association was observed between APS and other SSc-related manifestations, including PAH (online supplementary table 1). Among the 31 aPL-positive patients, 12 had ADU among whom all received calcium channel inhibitors, seven had bosentan, nine had low-dose aspirin while three received vitamin $\mathrm{K}$ antagonists or unfractioned heparin for APS (online supplementary table 2$)$. Forty-eight patients $(28.6 \%)$ had ADU (table 2). In univariate analysis, factors associated with ADU were positivity for anti- $\beta 2 \mathrm{GP} 1 \operatorname{IgG}(\mathrm{p}<0.001)$, anti-Scl70 $(\mathrm{p}=0.006)$ and higher mean mRSS (6.0 vs 14.0, $\mathrm{p}<0.001)$. Anti- $\beta 2 \mathrm{GP} 1$ positivity and mRSS remained significant in multivariate analysis (OR 8.71, 95\% CI 1.31 to 55.43 ; $\mathrm{p}=0.02$ and OR $1.06,95 \%$ CI 1.02 to 1.11 ; $\mathrm{p}=0.007$, respectively). When considering only 'high' aPL titres, anti- $\beta 2 \mathrm{GP} 1$ and anti- $\beta 2 \mathrm{GP} 1$ IgG remained significant ( $\mathrm{p}=0.003$ both) in univariate analysis, and anti$\beta 2 \mathrm{GP1}$ IgM was also associated with $\operatorname{ADU}(p=0.04)$. In multivariate analysis, only mRSS remained significantly associated with ADU (OR 1.07, 95\% CI 1.02 to 1.11; $\mathrm{p}=0.005$ ) with a trend towards anti- $\beta 2 \mathrm{GP} 1$ positivity (OR $5.27,95 \%$ CI 0.97 to $28.62 ; \mathrm{p}=0.054$ ) (online supplementary table 3) (online supplementary table 3). aPL, APS and past thrombotic event prevalences according to the different RP subsets are depicted in online supplementary table 4.

Overall, aPL prevalence in our population $(18 \%)$ is consistent with those recently reported in worldwide $(14 \%)$ and European $(15 \%)$ SSc populations, ${ }^{11}$ despite pronounced heterogeneity between studies in terms of aPL definition and technical methodology. We report an estimated APS prevalence in SSc of 4\%. Notwithstanding its rare occurrence, the association between APS and anti-Scl70 merits further evaluation.

Overall, anti- $\beta 2 \mathrm{GP} 1$ positivity was independently associated with ADU. A recent metanalysis did not find any association between overall aPL, LA, aCL or anti- $\beta 2 \mathrm{GP} 1$
Table 1 Patient characteristics

\begin{tabular}{|c|c|c|}
\hline \multicolumn{2}{|l|}{ Characteristics } & Patients $(n=168)$ \\
\hline \multicolumn{2}{|l|}{ Age, years $\pm S D$} & $57.8 \pm 15$ \\
\hline \multicolumn{2}{|l|}{ Female, $\mathrm{n}(\%)$} & $147(87.5)$ \\
\hline \multicolumn{3}{|l|}{ Smoking, $\mathrm{n}(\%)$} \\
\hline \multicolumn{2}{|l|}{ Current or past } & $20(12)$ \\
\hline \multicolumn{2}{|l|}{ Never } & $136(81)$ \\
\hline \multicolumn{2}{|l|}{ NA } & $12(7)$ \\
\hline \multicolumn{3}{|l|}{ SSc type, n (\%) } \\
\hline \multicolumn{2}{|l|}{ Limited } & $69(41)$ \\
\hline \multicolumn{2}{|l|}{ Diffuse } & $99(59)$ \\
\hline \multicolumn{2}{|l|}{ Disease duration, years $\pm \mathrm{SD}^{*}$} & $8.2 \pm 13.5$ \\
\hline \multicolumn{2}{|c|}{ Modified Rodnan skin score (0-51), mean (Q1, Q3) } & $8.0(4.0,19.0)$ \\
\hline \multicolumn{2}{|l|}{ ADU, n (\%) } & $48(29)$ \\
\hline \multicolumn{2}{|l|}{ Digital tip ulcerations, $\mathrm{n}(\%)$} & $44(26)$ \\
\hline \multicolumn{2}{|l|}{ Digital gangrene, n (\%) } & $4(3)$ \\
\hline \multicolumn{2}{|l|}{ Raynaud's severity score (0-4), mean (Q1, Q3) } & $1.0(1.0,3.0)$ \\
\hline \multicolumn{3}{|l|}{ PAH } \\
\hline \multicolumn{2}{|l|}{ Suspected PAH on echocardiography, $n(\%)$} & $19(11)$ \\
\hline \multicolumn{2}{|l|}{$\operatorname{sPAP}(\mathrm{mm} \mathrm{Hg})$, mean $\pm \mathrm{SD}$} & $31.8 \pm 13.7$ \\
\hline \multicolumn{2}{|l|}{$\mathrm{PAH}$ on $\mathrm{RHC}, \mathrm{n}(\%)$} & $12(7)$ \\
\hline \multicolumn{2}{|l|}{$\mathrm{mPAP}(\mathrm{mm} \mathrm{Hg}), \mathrm{mean}_{ \pm} \mathrm{SD}$} & $30.9 \pm 15$ \\
\hline \multicolumn{2}{|l|}{ LVEF on echocardiography (\%), mean \pm SD } & $66 \pm 9$ \\
\hline \multicolumn{2}{|l|}{ ILD, n (\%) } & $73(43)$ \\
\hline \multicolumn{2}{|l|}{ FVC, $\%$ predicted \pm SD } & $94.6 \pm 24.7$ \\
\hline \multicolumn{2}{|l|}{$\mathrm{DLCO}, \%$ predicted $\pm \mathrm{SD}$} & $69.1 \pm 21.1$ \\
\hline SSc-related autoantibodies, n (\%) & & \\
\hline Anticentromere, $\mathrm{n}(\%)$ & & $76(45)$ \\
\hline Anti-Scl70, n (\%) & & $60(36)$ \\
\hline LA, n (\%) & & $17(10)$ \\
\hline & Overall & High $(>40 \mathrm{U} / \mathrm{mL})$ \\
\hline aCL, n (\%) & & \\
\hline Any isotype (global) & $14(8)$ & $6(4)$ \\
\hline $\lg G$ & $11(6)$ & $6(4)$ \\
\hline $\lg M$ & $3(2)$ & $0(0)$ \\
\hline Anti-ß2GP1, n (\%) & & \\
\hline Any isotype & $14(8)$ & $10(6)$ \\
\hline $\lg G$ & $8(5)$ & $6(4)$ \\
\hline $\lg M$ & $8(5)$ & $4(3)$ \\
\hline$\geq 1 \mathrm{aPL}, \mathrm{n}(\%)$ & $31(18)$ & $26(15)$ \\
\hline Triple positivity, n (\%) & $3(2)$ & $1(1)$ \\
\hline APS, n (\%) & $7(4)$ & \\
\hline Related-arterial thrombosis, $\mathrm{n}(\%)$ & $4(2)$ & \\
\hline Related-venous thrombosis, $\mathrm{n}(\%)$ & $3(2)$ & \\
\hline Obstetrical manifestation, $\mathrm{n}(\%)$ & $0(0)$ & \\
\hline Overall arterial thrombosis history, $\mathrm{n}(\%)$ & $5(3)$ & \\
\hline Overall venous thrombosis history, $\mathrm{n}(\%)$ & $13(8)$ & \\
\hline
\end{tabular}

*Time from first non-Raynaud's symptom.

$\mathrm{aCL}$, anticardiolipin; ADU, active digital ulceration; $\mathrm{APL}$, antiphospholipid antibodies; APS, antiphospholipid syndrome; DLCO, diffusing capacity of the lung for carbon monoxide; FVC, forced vital capacity; $\beta 2 \mathrm{GP} 1$, beta-2 glycoprotein 1; Ig, immunoglobulin; ILD, interstitial lung disease; LA, lupus anticoagulant; LVEF, left ventricular ejection fraction; mPAP, mean pulmonary arterial pressure;NA, not available; PAH, pulmonary arterial hypertension; Q1/Q3, quartile 1/quartile 3; RHC, right heart catheterisation; SPAP, systolic pulmonary arterial pressure; SSc, systemic sclerosis. 
Table 2 Factors associated with ADU

\begin{tabular}{|c|c|c|c|c|}
\hline Characteristics & ADU- $(n=120)$ & $A D U+(n=48)$ & $P$ value & Adjusted OR $(95 \% \mathrm{Cl})^{*}$ \\
\hline Age, years $\pm S D$ & $58.9 \pm 15.5$ & $55.2 \pm 13.2$ & 0.15 & ND \\
\hline Female, n (\%) & 107 (89.2) & $40(83.3)$ & 0.31 & ND \\
\hline Smoking, $n(\%)$ & & & 0.43 & ND \\
\hline Current or past & $13(11)$ & $7(15)$ & & \\
\hline Never & $100(83)$ & $36(75)$ & & \\
\hline NA & $7(6)$ & $5(10)$ & & \\
\hline SSc type, n (\%) & & & 0.80 & ND \\
\hline Limited & $50(42)$ & $19(40)$ & & \\
\hline Diffuse & $70(58)$ & $29(60)$ & & \\
\hline Disease duration, years $\pm \mathrm{SD} \dagger$ & $7.3 \pm 12.7$ & $10.4 \pm 15.1$ & 0.19 & ND \\
\hline Modified Rodnan skin score (0-51), mean (Q1, Q3) & $6.0(2.0,14.5)$ & $14.0(8.0,26.0)$ & $<0.001$ & $1.06(1.02$ to 1.11$)(p=0.007)$ \\
\hline \multicolumn{5}{|l|}{ PAH } \\
\hline Suspected PAH on echocardiography, n (\%) & $13(11)$ & $6(13)$ & 0.76 & ND \\
\hline $\mathrm{sPAP}(\mathrm{mm} \mathrm{Hg}), \operatorname{mean} \pm \mathrm{SD}$ & $31.9 \pm 14.7$ & $31.5 \pm 10.9$ & 0.90 & \\
\hline $\mathrm{PAH}$ on $\mathrm{RHC}, \mathrm{n}(\%)$ & $8(7)$ & $4(8)$ & 0.70 & \\
\hline $\mathrm{mPAP}(\mathrm{mm} \mathrm{Hg})$, mean $\pm \mathrm{SD}$ & $31.8 \pm 9.6$ & $29.6 \pm 21.8$ & 0.73 & \\
\hline LVEF on echocardiography (\%), mean \pm SD & $65.4 \pm 9.8$ & $67.6 \pm 6.7$ & 0.23 & ND \\
\hline ILD, n (\%) & $47(39)$ & $26(54)$ & 0.08 & ND \\
\hline FVC, $\%$ predicted \pm SD & $97.3 \pm 17.4$ & $88.3 \pm 26.9$ & 0.09 & ND \\
\hline DLCO, \% predicted \pm SD & $71 \pm 21.2$ & $64.8 \pm 20.4$ & 0.14 & ND \\
\hline \multicolumn{5}{|l|}{ SSc-related autoantibodies, n (\%) } \\
\hline Anticentromere, $\mathrm{n}(\%)$ & $60(50)$ & $16(33)$ & 0.05 & $0.64(0.2$ to 1.87$)$ \\
\hline Anti-Scl70, n (\%) & $35(29)$ & $25(52)$ & 0.006 & 2.55 (0.91 to 7.14$)$ \\
\hline \multicolumn{5}{|l|}{ aPL, n (\%) } \\
\hline LA & $10(8)$ & $7(15)$ & 0.22 & ND \\
\hline aCL (overall positivity) & $11(9)$ & $3(6)$ & 0.54 & ND \\
\hline $\lg G$ & $8(7)$ & $2(4)$ & 0.57 & ND \\
\hline $\lg M$ & $2(2)$ & $1(2)$ & 0.83 & ND \\
\hline Anti- $\beta 2 \mathrm{GP} 1$ (overall positivity) & $5(4)$ & $9(19)$ & 0.002 & $8.71(1.31$ to 55.43$)(p=0.02)$ \\
\hline $\lg G$ & $1(1)$ & $7(16)$ & $<0.001$ & ND \\
\hline $\lg M$ & $4(4)$ & $4(9)$ & 0.17 & ND \\
\hline APS, n (\%) & $4(3)$ & $3(6)$ & 0.39 & ND \\
\hline Overall arterial thrombosis history, $\mathrm{n}(\%)$ & $3(3)$ & $2(4)$ & 0.61 & ND \\
\hline Overall venous thrombosis history, $\mathrm{n}(\%)$ & $12(10)$ & $1(2)$ & 0.08 & ND \\
\hline
\end{tabular}

*Logistic regression with adjustment for anticentromere, anti-Scl70, modified Rodnan skin score, smoking, the presence of LA and/or aCL.

†Time from first non-Raynaud's symptom.

aCL, anticardiolipin; ADU, active digital ulceration; aPL, antiphospholipid antibodies; APS, antiphospholipid syndrome; DLCO, diffusing capacity of the lung for carbon monoxide;

FVC, forced vital capacity; $\beta 2 \mathrm{GP} 1$, beta-2 glycoprotein 1; Ig, immunoglobulin; IPD, interstitial pulmonary disease; LA, lupus anticoagulant; LVEF, left ventricular ejection fraction; mPAP, mean pulmonary arterial pressure; NA, not available ;ND, not done; PAH, pulmonary arterial hypertension; Q1/Q3, quartile 1/quartile 3; RHC, right heart catheterisation; sPAP, systolic

pulmonary arterial pressure; SSc, systemic sclerosis.

positivity and digital ulcers. ${ }^{11}$ Only three studies have specifically evaluated IgG and/or IgM aCL prevalence in patients with SSc with or without digital ulcer, and no difference was observed. ${ }^{3}$ Only one study has shown an independent association between active digital ischaemia and IgM anti- $\beta 2 \mathrm{GP} 1$ positivity, using the same definition of ADU as us. ${ }^{8}$ On the other hand, another study reported an association between aCL positivity and elevated von Willebrand antigen factor. ${ }^{12}$ Taken together, these results suggest possible associations between aPL positivity and endothelial injury in SSc, and this relationship deserves further evaluation.
The main strength of our study was to only consider confirmed aPL and subanalyses with high titres of aPL, thereby avoiding potential bias of transient and non-clinically relevant aPL. Moreover, distinction of each aPL type and isotype was made for assessment of potential associations with ADU. Lastly, our results reflect a real-life prevalence study of aPL in SSc with aPL assays having been performed in each centre.

Our study has several limitations. First, the lack of power precluded multivariate analysis for aCL and anti- $\beta 2 \mathrm{GP} 1$ isotypes and probably explains the loss of significance for the association between 'high' anti- $\beta 2 \mathrm{GP} 1$ positivity 
and ADU. Moreover, the low number of patients with APS calls for cautious interpretation of the data. Second, thrombosis history was collected retrospectively, leading to potential memorisation and selection bias.

In conclusion, this study found an aPL prevalence in SSc of $18 \%$. Anti- $\beta 2 \mathrm{GP} 1$ positivity is an independent factor associated with $\mathrm{ADU}$ and might be preferentially related to positivity of antiB2GP1 IgG isotype. These data provide additional insights into the role of aPL in SSc vasculopathy.

\author{
Author affiliations \\ ${ }^{1}$ Internal Medicine, Poitiers University Hospital, Poitiers, France \\ ${ }^{2}$ Internal Medicine, Colmar Civilian Hospitals, Colmar, France \\ ${ }^{3}$ Rheumatology, National Reference Center for Rare Autoimmune Diseases (RESO), \\ Strasbourg University Hospital, Strasbourg, France \\ ${ }^{4}$ Internal Medicine, National Reference Center for Rare Autoimmune Diseases \\ (RES0), Strasbourg University Hospital, Strasbourg, France \\ ${ }^{5}$ Clinical Immunology, National Reference Center for Rare Autoimmune Diseases \\ (RESO), Strasbourg University Hospital, Strasbourg, France \\ ${ }^{6}$ Internal Medicine, Mulhouse Regional Hospital Center, Mulhouse, France \\ ${ }^{7}$ Internal Medicine and Clinical Immunology, Dijon University Hospital, Dijon, France \\ ${ }^{8}$ Vascular Medicine, Regional Center for Rare Vascular and Systemic Autoimmune \\ Diseases, Nancy University Hospital, Vandoeuvre-Les-Nancy, France \\ ${ }^{9}$ Medicine Faculty, University of Lorraine, Vandoeuvre-Les-Nancy, France \\ ${ }^{10}$ Internal Medicine, Metz-Thionville Regional Hospital Center, Metz, France \\ ${ }^{11}$ Rheumatology, Reims University Hospital, Reims, France \\ ${ }^{12}$ Internal Medicine, Besancon University Hospital, Besançon, France
}

Contributors All authors approved the entirety of the submitted material and contributed actively to the study and all of them meet the journal's criteria for authorship.

Funding The authors have not declared a specific grant for this research from any funding agency in the public, commercial or not-for-profit sectors.

Competing interests None declared.

Patient consent for publication Not required.

Ethics approval The study was approved by local ethics committee.

Provenance and peer review Not commissioned; externally peer reviewed.

Open access This is an open access article distributed in accordance with the Creative Commons Attribution Non Commercial (CC BY-NC 4.0) license, which permits others to distribute, remix, adapt, build upon this work non-commercially, and license their derivative works on different terms, provided the original work is properly cited, appropriate credit is given, any changes made indicated, and the use is non-commercial. See: http://creativecommons.org/licenses/by-nc/4.0/.

\section{REFERENCES}

1. Mostmans $\mathrm{Y}$, Cutolo M, Giddelo $\mathrm{C}$, et al. The role of endothelial cells in the vasculopathy of systemic sclerosis: a systematic review. Autoimmun Rev 2017;16:774-86.

2. Chighizola $\mathrm{CB}$, Raschi $\mathrm{E}$, Borghi $\mathrm{MO}$, et al. Update on the pathogenesis and treatment of the antiphospholipid syndrome. Curr Opin Rheumatol 2015;27:476-82.

3. Merashli M, Alves Jose'Delgado, Ames PRJ. Clinical relevance of antiphospholipid antibodies in systemic sclerosis: a systematic review and meta-analysis. Semin Arthritis Rheum 2017;46:615-24.

4. van den Hoogen F, Khanna D, Fransen J, et al. 2013 classification criteria for systemic sclerosis: an American College of rheumatology/ European League against rheumatism collaborative initiative. Ann Rheum Dis 2013;72:1747-55.

5. LeRoy EC, Black C, Fleischmajer R, et al. Scleroderma (systemic sclerosis): classification, subsets and pathogenesis. J Rheumatol 1988;15:202-5.

6. Clements PJ, Lachenbruch PA, Seibold JR, et al. Skin thickness score in systemic sclerosis: an assessment of interobserver variability in 3 independent studies. J Rheumatol 1993;20:1892-6.

7. Medsger TA, Silman AJ, Steen VD, et al. A disease severity scale for systemic sclerosis: development and testing. J Rheumatol 1999;26:2159-67.

8. Boin F, Franchini S, Colantuoni E, et al. Independent association of anti-beta(2)-glycoprotein I antibodies with macrovascular disease and mortality in scleroderma patients. Arthritis Rheum 2009;60:2480-9.

9. Miyakis S, Lockshin MD, Atsumi T, et al. International consensus statement on an update of the classification criteria for definite antiphospholipid syndrome (APS). J Thromb Haemost 2006;4:295-306.

10. Pengo V, Tripodi A, Reber G, et al. Update of the guidelines for lupus anticoagulant detection. Subcommittee on lupus Anticoagulant/ Antiphospholipid antibody of the scientific and standardisation Committee of the International Society on thrombosis and haemostasis. J Thromb Haemost 2009;7:1737-40.

11. Sobanski V, Lemaire-Olivier A, Giovannelli J, et al. Prevalence and clinical associations of antiphospholipid antibodies in systemic sclerosis: new data from a French cross-sectional study, systematic review, and meta-analysis. Front Immunol 2018;9:2457.

12. Assous N, Allanore $\mathrm{Y}$, Batteux F, et al. Prevalence of antiphospholipid antibodies in systemic sclerosis and association with primitive pulmonary arterial hypertension and endothelial injury. Clin Exp Rheumatol 2005;23:199-204. 